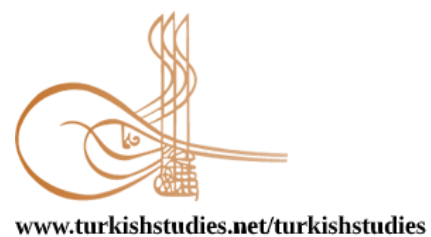

\author{
Turkish Studies \\ eISSN: $1308-2140$ \\ Research Article / Araştırma Makalesi
}

BALKAN

INTVERSTY

Sponsored by IBU

\title{
Müzeler Karantinada!
}

Museums in Quarantine!

Nevra Ertürk*

\begin{abstract}
In this period when the current definition, functions, fields of activity and digitalization process of museums were discussed, the World Health Organization's announcement of pandemic due to the new coronavirus marked the beginning of a new area in the museum sector, as in all sectors. Although museums try to maintain intellectual and facility access through digital platforms or online activities during their closures, it is clear that the conservation and security measures of building and collections as well as staff, visitor and event management will be revised. According to the results of the researches conducted to evaluate the impact of the pandemic process on museums, it is foreseen that the small-scale museums and museums supported by private funds will face financial problems in the post-pandemic period, and some of the museums will not be opened to the visitors again. On the other hand, museum directors and experts have started to work on issues such as financial needs of the museum and staff, facility management, conservation and security measures of collections, museum communication activities during and after the pandemic period as well as pandemic preparedness and response plans. In this context research questions of the article are as follows: What are the social duties and responsibilities of museums during the pandemic period? What is the effect of pandemic on the functioning of museums? How should be the pandemic preparedness and response plans of museums? How should museums provide intellectual and facility access when physical access is not possible? What are the elements that will ensure the sustainability of museums in the post-pandemic period? The purpose of article is to provide information about the social role of museums during the pandemic period; conservation and security of collections and pandemic preparedness plans of museums; short and long term effects of the pandemic period on museums; digital platforms and online activities preferred by museums as a means of communication; and to propose steps to be taken. While the scope of article is limited with the studies and practices of museums and museum associations in abroad, findings and recommendations will not only valid for museums and museum field in abroad, but also for Turkey. Literature review was used a research method in the article; current pandemic and museum related researches and reports of the international museum associations; websites, online activities, electronic publications and social media accounts of museums and related institutions in abroad were examined. In the article, the positive and negative effects of pandemic to the museums are evaluated; it is concluded that pandemic and post-pandemic period provide an opportunity for reconsideration of the current museum definition, functions, management and fields of activity both for museums in abroad and Turkey.
\end{abstract}

\footnotetext{
* Doç. Dr., Yıldız Teknik Üniversitesi, Mimarlık Fakültesi, Kültür Varlıklarını Koruma ve Onarım Bölümü Assoc. Prof. Dr., Yildiz Technical University, Faculty of Architecture, Department of Conservation and Restoration of Cultural Property 
Structured Abstract: Museums have changed in terms of their definitions, functions, field of activities or management approach since their birth. Conservation, research and communication are the basic functions of museums. Today museums are community-centered and shaped their functions as well as activities according to the new museological approach. Visitor management, participation, inclusion, sustainable museums are the new terms that included in the field of museology. In the $20^{\text {th }}$ century, some of the museums digitized their collections and shared them via web pages; digital applications were used as a communication tool especially in exhibitions and educational activities; virtual museums or online exhibitions were launched. While the functions of museums, their working areas and the digitalization process are being discussed, museums that are temporarily closed due to the pandemic, can only offer digital experiences during their closures.

When the World Health Organization (WHO) declared pandemic due to the new coronavirus (COVID-19) on March 11, 2020, the whole world has been under the influence of the new coronavirus, from the health sector to the education, from science to culture and art. Museums are one of the most effected institutions within the cultural sector. Many museums areound the world are well-prepared against natural disasters, theft or vandalism. However, pandemic is a new term for museums. In this respect, new practices and approaches have started to be discussed during and after the pandemic process. Museums and museum associations moved quickly in line with the recommendations of WHO, national and regional organizations. Museums have started to review their existing emergency plans and prepare for the post-pandemic period in terms of museum management, conservation and security of collections, facility management, museum communication activities or visitor management.

In this context, main research questions of the article are as follows: What are the social duties and responsibilities of museums during the pandemic period? What is the effect of pandemic on the functioning of museums? How should be the pandemic preparedness and response plans of museums? How should museums provide intellectual and facility access when physical access is not possible? What are the elements that will ensure the sustainability of museums in the post-pandemic period? The article consists of four parts. These are: Social Role of Museums in the Social Isolation Process; Conservation and Security in Museums Against the New Generation Risk; Management and Financial Effects of the Pandemic Period on Museums and Museum Communication During the Pandemic Period. Each part is supported with report findings, examples from museums and concluded with recommendations. The purpose of article is to provide information about the social role of museums during the pandemic period; conservation and security of collections and pandemic preparedness plans of museums; short and long term effects of the pandemic period on museums; digital platforms and online activities preferred by museums as a means of communication; and to propose steps to be taken. The scope of article is limited with the studies and practices of museums and museum associations in abroad, however, findings and recommendations will be valid for museums and museum field all around the world including Turkey.

Literature review was used as a research method in the article. Various museum associations and leading institutions in the museology field have conducted site surveys and shared their findings through reports. International Council of Museums' (ICOM) report entitled 'Museums, museum professionals and COVID-19"; United Nations Educational, Scientific and Cultural Organization's (UNESCO) report entitled "Museums around the World in the face of COVID-19"; Network of European Museum Organisations' (NEMO) report entitled "Survey on the impact of the COVID-19 situation on museums in Europe"; Art Fund's report entitled "COVID-19 Impact: Museum Sector Research Findings Summary", and Istanbul Foundation for Culture and Arts' (IKSSV) report entitled "The Uniting Power of Arts and Needs of the Cultural Field During the Pandemic" are the main references of the article. Although the research results do not give information about museums all over the world, but they contain important data in terms of a general situation assessment. Report findings also provide up to date data from the site. Besides the aforementioned reports, websites, online activities, electronic publications and social media accounts of museums and related institutions in abroad were also examined.

According to the aforementioned report findings, the main problem that museums will face after the pandemic period due to the decrease in museum revenues is the financial resource shortage. It is foreseen that the small-scale museums and museums supported by private funds will face financial problems in the postpandemic period, and some of the museums will not be opened again. On the other hand, maintenance and security of buildings and collections, process management with full time and part time staff, volunteers or partners; visitor management; event management in museum premises and online; the scope of the intellectual access in the post-pandemic period are also the other main concerns of museums. 
Consequently, museums around the world faced with a new situation and process management. Government emergency funds including museums, tax-deferral or exemption will help museums in the forthcoming months. On the other hand, comprehensive planning and visitor surveys are required in all fields of museum activity. In addition to the physical accesibility of museums, it should be reconsidered how different types of digital applications can be used as an effective tool of communication. This period can also be accepted as an opportunity to review many issues related to museums such as definition, functions, areas of activity or museum management. It is clear that research projects, sector research or analysis conducted by museums, museum associations and universities, will contribute to the field of museology.

Keywords: Museology, Museum Management, Museum Communication, Risk Management, Pandemic

Öz: Müzelerin mevcut tanımı, işlevleri, faaliyet alanları ve dijitalleşme sürecinin tartışıldığı bu dönemde, Dünya Sağlık Örgütü’nün yeni koronavirüs sebebiyle pandemi ilân etmesi, tüm sektörlerde olduğu gibi, müzecilik sektöründe de yeni bir dönemin başlayacağının işareti olmuştur. Pandemi döneminde ziyarete kapanan müzeler, entelektüel ve olanaklara erişimi dijital platformlar veya çevrimiçi etkinlikler aracilığıyla devam ettirmeye çalışalar da, gerek bina ve koleksiyonların koruma ve güvenlik önlemlerinin gerekse personel, ziyaretçi ve etkinlik yönetiminin gözden geçirileceği açıktır. Pandemi sürecinin müzelere etkisini değerlendirmek üzere yapılan uluslararası ölçekteki araştırma sonuçlarına göre, pandemi sonrası dönemde küçük ölçekli müzeler ile özel fonlarla desteklenen müzelerin finansal sorunlarla karşı karşıya kalacağı, bazı müzelerin ise tekrar ziyarete açılamayacağı öngörülmektedir. Öte yandan müze yöneticileri ve uzmanlar, pandemi dönemi ve sonrasında müze ve personelin finansal ihtiyaçları, bina yönetimi, koleksiyonların korunması ve güvenliği, müzelerin iletişim etkinlikleri, pandemi hazırlık ve müdahale planları gibi konularla ilgili çalışmaya başlamışlardır. Bu çerçevede makalenin araştırma soruları şunlardır: Pandemi döneminde müzelerin toplumsal görev ve sorumlulukları nelerdir? Pandeminin müzelerin işleyişine etkisi nedir? Müzelerin pandemi hazırlık ve müdahale planları nasıl olmalıdır? Fiziksel erişimin mümkün olmadığı pandemi döneminde müzeler entelektüel ve olanaklara erişimi nasıl sağlamalıdırlar? Pandemi sonrası dönemde müzelerin sürdürülebilirliğini sağlayacak unsurlar nelerdir? Makalenin amacı; pandemi döneminde müzelerin toplumsal rolü; koleksiyonların korunması ve güvenliği ile müzelerin pandemi hazırlık planları; pandemi döneminin müzelere kısa ve uzun vadeli etkileri; müzelerin iletişim aracı olarak tercih ettikleri dijital platformlar ve çevrimiçi etkinlikler hakkında bilgi vermek, atılacak adımlara dair öneriler sunmaktadır. Makalenin kapsamı yurt dışındaki müzeler ve müzecilik birliklerinin çalışmaları ve uygulamaları ile sınırlı tutulmuş olmakla birlikte, tespitler ve öneriler sadece yurt dışındaki müzeler ve müzecilik alanı için değil, Türkiye için de geçerli olacak niteliktedir. Makalede araştırma yöntemi olarak literatür tarama kullanılmış; uluslararası alanda hizmet veren müzecilik birliklerinin pandemi ve müzelerle ilgili güncel araştırmaları ve raporları; yurt dışındaki müzelerin ve ilgili kurumların web siteleri, çevrimiçi etkinlikleri, elektronik yayınları ve sosyal medya hesapları incelenmiştir. Makalede pandeminin müzelere olumlu ve olumsuz yönden etkileri değerlendirilmekte; pandemi dönemi ve sonrasının gerek yurt dışındaki gerekse Türkiye'deki müzeler için, müzelerin mevcut tanımı, işlevleri, yönetimi ve faaliyet alanlarının tekrar gözden geçirilmesi yönünde firsat sağladığı sonucuna varılmaktadır.

Anahtar Kelimeler: Müzebilim, Müze Yönetimi, Müze İletişimi, Risk Yönetimi, Pandemi

\section{Giriş}

Uluslararas1 Müzeler Konseyi'nin (International Council of Museums-ICOM) 2019 tarihinde Kyoto'da gerçekleştirdiği 34. Genel Kurulu'nda görüşmeye açılan yeni müze tanımı ulusal ve uluslararası alanda tartış1ırken, müzeler pandemi nedeniyle çalışmalarına geçici bir süre ara vermek zorunda kalmışlardır. Artık müzelerin gündemi yeni koronavirüs (COVID-19) ve pandeminin müzelere etkisidir.

Dünya Sağlık Örgütü’nün (World Health Organization-WHO) 11 Mart 2020 tarihinde yeni koronavirüs sebebiyle pandemi ilân etmesi ile sağl1k sektöründen eğitim sektörüne, bilimden kültür ve sanat alanına kadar tüm dünya yeni koronavirüsün etkisi altında kalmıştır. Kültür mirası alanında çalışan uzmanlar, taşınır ve taşınmaz kültür varlıkları, sit alanları, peyzaj alanları, somut olmayan kültür mirası ile ilgili alınabilecek önlemleri ve atılacak adımları tartışırken, ICOM, 
Birleşmiş Milletler Eğitim, Bilim ve Kültür Kurumu (United Nations Educational, Scientific and Cultural Organization-UNESCO), Amerikan Müzeler Birliği (American Alliance of MuseumsAAM), Avrupa Müzeleri Organizasyon Ağ1 (Network of European Museum OrganisationsNEMO) başta olmak üzere, müzecilikle ilgili birçok kurum ve kuruluş, pandeminin müzelere etkisi ile ilgili çevrimiçi anket ya da sektör analizi yapmıştır. Bir yandan araştırma sonuçları rapor olarak kamuoyuyla paylaşılırken bir yandan da pandeminin müzelere etkisi çevrimiçi toplantılarda tartış1maya devam etmektedir.

20. yüzyılda başlayan Dijital Çağ ile birlikte bazı müzeler koleksiyonlarını dijitalleştirip, web sayfaları aracıllı̆ı ile paylaşmış; dijital uygulamalar özellikle sergilerde ve eğitim faaliyetlerinde araç olarak kullanılmış; sanal müzeler ya da çevrimiçi sergiler açılmaya başlanmıştır. Bu çerçevede, müzelerin iletişim işlevi ve toplum odaklı olma yaklaşımları Dijital Çağ ile birlikte çeşitlenmiştir.

21. yüzyılda müzelerin işlevleri, çalışma alanları ve dijitalleşme sürecinin müzeler için ne anlam ifade ettiği tartışlırken, pandemi nedeni ile geçici süre ile ziyarete kapanan müzeler çevrimiçi etkinlikler ve sosyal medya hesapları aracılığıyla ziyaretçileri ile iletişim kurmakta, karantina döneminde evlerinde zaman geçiren mevcut ve potansiyel ziyaretçilere deneyim alanlarını hatırlatmakta ya da yeni deneyim alanları sunmaktadırlar.

Deprem, sel, yangın gibi doğal afetler, hırsızlık ya da vandalizme karşı hazırlıklı olan ya da ön çalışmaları bulunan müzeler, pandemi odaklı yeni bir süreç yönetimi ile karşı karşıyadırlar. $\mathrm{Bu}$ çerçevede, ICOM ile Ekonomik İşbirliği ve Kalkınma Teşkilatı (Organisation for Economic Cooperation and Development-OECD) ortaklığında 10 Nisan 2020'de "Coronovirus (COVID-19) and museums: Impact, innovations and planning for post-crisis" başlıklı çevrimiçi bir toplantı gerçekleştirilmiştir. Toplantıda, mevcut krizin müzelere kısa ve uzun vadeli etkileri; müzeler tarafından önerilen yaratıcı çözümler; krizin müzeler ve ekosistemine etkilerini azaltmak üzere ulusal ve yerel yönetimler tarafından ortaya konulacak politikalar tartışılmıştır (ICOMe, 2020).

Pandemi döneminde müzelerin toplumsal görev ve sorumlulukları nelerdir? Pandeminin müzelerin işleyişine etkisi nedir? Müzelerin pandemi hazırlık ve müdahale planları nasıl olmalıdır? Fiziksel erişimin mümkün olmadığ 1 pandemi döneminde müzeler entelektüel ve olanaklara erişimi nasıl sağlamalıdırlar? Pandemi sonrası dönemde müzelerin sürdürülebirliğini sağlayacak unsurlar nelerdir? gibi sorular müzecilik alanında yeni tartışmaların ve yaklaşımların ortaya çıkmasına katkı sağlayacaktır. Pandemi döneminin müzelere kısa ve uzun vadeli etkilerini değerlendirmek üzere Mayıs 2020'de yayımlanan dört rapor makalede kaynak olarak kullanılmıştır. Bunlar: ICOM'un "Museums, museum professionals and COVID-19"'; UNESCO'nun "Museums around the World in the face of COVID-19"; NEMO'nun "Survey on the impact of the COVID-19 situation on museums in Europe" ve Art Fund'un "COVID-19 Impact: Museum Sector Research Findings Summary" başlıklı raporlarıdır. Araştırma sonuçları her ne kadar tüm dünyadaki müzeler hakkında bilgi vermese de, genel bir durum değerlendirmesine katkı sağlayacak niteliktedirler.

\footnotetext{
${ }^{1}$ ICOM tarafından çevrimiçi yayımlanan rapor, 7 Nisan-7 Mayıs 2020 tarihleri arasında ICOM tarafindan yürütülen araştırmanın sonuç raporudur. Araştırmaya 5 kıtadan 107 ülke, 1600 müze ve müze uzmanı yanıt vermiştir (ICOMb, 2020).

${ }^{2}$ UNESCO tarafından çevrimiçi yayımlanan rapor, 16 Nisan-20 Mayıs 2020 tarihleri arasında UNESCO'nun 51 Saha Ofisi tarafından gerçekleştirilen, 88 Üye Ülke'den derlenen bilgiler ile farklı müzecilik birlikleri ve ajansları tarafından toplanan verilerden oluşmaktadır (UNESCO, 2020).

3 NEMO tarafından çevrimiçi yayımlanan rapor, yeni koronavirüsün müzecilik sektörü üzerindeki ekonomik etkisini belgelemek ve değerlendirmek üzere, 24 Mart-30 Nisan 2020 tarihleri arasında gerçekleştirilen bir araştırmanın sonucudur. Araştırmaya 48 ülkeden (ağırlıklı olarak Avrupa ülkeleri) yaklaşık olarak 1000 müze katılmıştır (NEMO, 2020).
}

Turkish Studies, 15(4) 
Pandemi döneminde müzelerin kapalı kalmasının sadece ekonomik değil, toplumsal boyutu da mevcuttur. Müzeler sadece ortak mirası korumakla kalmamakta, aynı zamanda eğitim ve diyaloğu yaymakta, toplum için ilham kaynağı olmaktadırlar. Müzeler sosyal uyumu güçlendirmekte, yaratıc1lığı teşvik etmekte ve kolektif hafizayı aktarmaktadırlar. Sürdürülebilir ekonomik kalkınmanın parçası olan turizmin tanıtımında da müzelerin rolü büyüktür (UNESCO, 2020).

$\mathrm{Bu}$ çerçevede makale dört bölümden oluşmaktadır. Birinci bölümde müzelerin toplumsal görev ve sorumlulukları yurt dışından örneklerle açıklanmakta; ikinci bölümde müzelerin hazırlıklı olmadığ 1 salgın hastalık ve pandemi konusundaki mevcut durum, koruma, güvenlik ve risk yönetimi çalışmaları hakkında bilgi verilmekte; üçüncü bölümde pandeminin müzelere idari ve finansal açıdan etkileri uluslararası raporlardaki veriler çerçevesinde değerlendirilmekte ve öneriler sunulmakta; dördüncü bölümde pandemi döneminde müzelerin çevrimiçi etkinlikleri hakkında bilgi verilmekte, dijitalleşme sürecinin avantaj ve dezavantajları değerlendirilmektedir. Makalenin sonuç bölümünde ise, müzeler açınsından pandemi sürecinin olumlu ve olumsuz yönleri açıklanmakta, pandemi odaklı müze yönetimine dair öneriler sunulmakta, müzelerin kısa ve uzun vadeli planlamalarında dikkat edilmesi gereken hususlar vurgulanmaktadır.

\section{Sosyal İzolasyon Sürecinde Müzelerin Toplumsal Rolü}

AAM, toplumda en güvenilir kurumlardan biri olarak müzelerin kabul edildiğini ve böyle bir kriz döneminde de müzelerin güvenilir kurumların başında geldiğini belirtmekte; toplumsal rolü gereği müzelerin düzenleyecekleri toplumu bilgilendirme faaliyetleri ile dezenformasyon yayılımına karşı mücadele edilebileceğini vurgulamaktadır (AAMe, 2020).

Toplum yararına hizmet veren müzeler bu süreçte başta WHO olmak üzere, ilgili diğer ulusal ve uluslararası kuruluşların beyanlarını ya da bilgi dokümanlarını, web siteleri, sosyal medya hesapları ya da blogları aracılığıyla paylaşmaktadırlar. Bu tür faaliyetler her müzenin çalışma alanı ya da koleksiyonları ile doğrudan bağlantılı olmasa da yeni koronavirüsle ilgili farkındalığı artırmak ve alınabilecek önlemleri hatırlatmak müzelerin toplumsal görevidir.

New York’taki Ulusal Doğa Tarihi Müzesi’nde 2018 yılında açılan ve 2021 yılına kadar açık kalması planlanan "Outbreak: Epidemics in a Connected World" sergisi (National Foundation for Infectious Diseases, 2018), müzelerin toplumsal görev ve sorumluklarına iyi bir örnektir. Sergide, toplumsal farkındalığı artırmak amacıyla bulaşıcı hastalıkların nasıl başladığı ve yayıldığı hakkında ziyaretçilerle bilgi paylaşılmakta; küresel seyahat ve ticaret, kentleşme gibi insan faaliyetlerinin dünya çapında epidemik ve pandemik riskleri güçlendiren faktörler olduğu belirtilmektedir. Sergi kapsamında, toplum sağlı̆̆ına yönelik risklerin yayılmasını azaltıcı faaliyetlerle ilgili bir iletişim platformu da oluşturulmuştur (Sholts, 2020).

Toplum sağlığına yönelik farkındalık artıracak bir diğer örnek ise, Almanya'nın Cottbus kentindeki Brandenburg Devlet Modern Sanat Müzesi'nde açılması planlanan sergilerdir. Süreli sergilerde, pandemi döneminde kullanılan nesneler ile yeni dönemin sosyal mesafe kuralları toplumla paylaşılacaktır (Hickley, 2020).

A.B.D'deki müzeler tarafından başlatılan \#MuseumMomentofZen (\#SakinlikAnıMüzesi) sosyal medya hesabı ile insanlar tedavi edici ya da iyileştirici bir araç olarak sanat eserlerinin fotoğraflarını veya videolarını paylaşmaktadırlar (AAMc, 2020). Sadece sanat müzeleri değil, diğer müzelerin koleksiyonları da hem iyileştirici hem de ilham verici kaynaklardır. Pandemi dönemi ve sonrasında bu tür sosyal medya hesaplarının oluşturulması ve katılımın teşvik edilmesi, toplumsal iyileşmeye, yaratıcılığa katkı sağlayacak nitelikte faaliyetlerdir.

ICOM'un 2007 tarihli müze tanımında da ifade edildiği gibi, müzeler toplumun ve gelişimin hizmetinde bilgi paylaşmaktadırlar. Nitekim pandemi döneminde de müzeler çevrimiçi 
sürekli ve süreli sergiler, kültürel, sanatsal, eğitsel etkinlikler ya da yayınlar aracilığıyla bilgi paylaşımını devam ettirmişlerdir.

\section{Yeni Nesil Riske Karşı Müzelerde Koruma ve Güvenlik}

ICOM'un "Museums, museum professionals and COVID-19" başlıklı raporunda yer alan araştırmaya katılanların \%80'ni pandemi döneminde müzelerde koruma ve güvenlik önlemlerinin sürdürüldüğünü; mevcut personel sayısının azalması nedeni ile önlemlerin artırıldığını belirtmektedir. Öte yandan, araştırmaya yanıt verenlerin \%11'i mevcut güvenlik önlemlerin yetersiz olduğunu ve pandemi özelinde ek önlemlere ihtiyaç duyulduğunu vurgulamaktadırlar. Pandemi döneminde bağıl nem, sıcaklık gibi çevresel koşulları sabit değerlerde tutmanın başlıca sorunlar arasında yer aldığı belirtilmekte; katılımcıların \%18'den fazlası ise, koleksiyonların korunması ile ilgili mevcut sistemlerin yeterli olmadığını vurgulamaktadırlar (ICOMb, 2020).

ICOM Uluslararas1 Konservasyon Komitesi (ICOM International Committee for Conservation-ICOM-CC) $)^{4}$, Uluslararası Kültür Varlıklarını Koruma ve Onarım Çalışmaları Merkezi (International Centre for the Study of the Preservation and Restoration of Cultural Property-ICCROM) ${ }^{5}$, Kanada Konservasyon Enstitüsü (Canadian Conservation Institute-CCI) ${ }^{6}$, Smithsonian Kültürle İlgili Kurtarma Girişimi (Smithsonian Cultural Rescue Initiative) ${ }^{7}$ başta olmak üzere birçok organizasyon, bina, koleksiyon, personel ve ziyaretçi için pandemi öncesinde, pandemi dönemi ve sonrasında rehberlik edecek el kitaplanı, ilkeler, standartlar, kontrol listeleri veya videolar yayımlamış; ilgili uzman personelin görev ve sorumluklarını yeniden tanımlanmıştır.

Yeni koronavirüs koleksiyondaki nesneler ya da müzedeki yüzeyler aracılığı ile insanlara geçer mi? Virüs yüzeylerde ne kadar süre ile kalıyor? Koleksiyonların muhafaza edildiği sergi salonları ve depo alanlarındaki çevresel koşullar virüsün yüzeyde kalma süresini etkiler mi? Müzede insan sağlığına zarar vermeden dezenfekte işlemi nasıl yapılır? Pandemi sürecinde müzede yangın ya da su baskını olursa, koleksiyona nasıl müdahale edilir? gibi konularda uzmanlar çalışmaktadırlar.

Müzeler, deprem, yangın, sel gibi bölgesel veya ulusal ölçekteki öncelikleri kapsamında eylem planları hazırlamakta ve uygulamaktadırlar. Öte yandan dünya genelinde az sayıda müzenin pandemi planı mevcuttur. Müzelerin acil durum ya da afet yönetimi planlarında ise 'pandemi' konusunun sınırlı sayıda olduğu tespit edilmiştir.

A.B.D.'nin Boston şehrindeki Bilim Müzesi’nin 'Salgın Hastalık \& Pandemi Müdahale Politikası" yeni koronavirüs kapsamında 2020 yılının Mart ayında güncellemiştir. Söz konusu politika çerçevesinde yürüten plan, salgın hastalıkların izlenmesi, hazırlık ve müdahale konusunda müzeye rehberlik etmektedir. Salgın hastalıkların arttığı durumda veya WHO pandemi ilân ettiğinde, Kriz Yönetim Planı'nın parçası olarak “Pandemi Müdahale Planı” yürürlüğe girmektedir. Plan, pandemi öncesi, pandemi dönemi ve sonrası olmak üzere üç aşamadan oluşmakta ve her süreç için atılacak adımları içermektedir (Museum of Science, 2020).

A.B.D.'nin Virginia Eyaleti’nde bulunan Amerikan İç Savaș Müzesi’nin “COVID-19 Eylem Planı" ise henüz taslak aşamasında olup, planda üç ana strateji mevcuttur. Bunlar: Müzenin

\footnotetext{
4 Konuyla ilgili yayınlar için bkz. https://icom.museum/en/covid-19/resources/conservation-of-musem-collections/ (ICOMc, 2020).

5 Konuyla ilgili yayınlar için bkz. https://www.iccrom.org/sites/default/files/COVID19\%20Collections\%20Care\%20Resources.pdf (Kennedy, 2020).

${ }^{6}$ Konuyla ilgili yayınlar için bkz. https://www.canada.ca/en/conservation-institute/services/conservation-preservationpublications/canadian-conservation-institute-notes/caring-heritage-collections-covid19.html (CCI, 2020).

7 Konuyla ilgili yayınlar için bkz. https://culturalrescue.si.edu/hentf/major-disasters/current-disasters/\#section6 (Smithsonian Cultural Rescue Initiative, 2020).
} 
alanlarını temiz tutmak ve dezenfekte etmek; müze personelinin sağlık durumunu korumak ve olası finansal etkileri tespit etmektedir (AAMd, 2020).

Çocuk Müzeleri Birliği'nin (Association of Children's Museums-ACM) 28 Şubat 2020 tarihinde güncellediği "Müzenizin Yenikoronavirüse Karşı Müdahale Rehberi” başlıklı dokümanda, kurum iç ve kurum dışı protokol olmak üzere iki ana eylem planı mevcuttur. Örneğin; idari olarak, müzelerin acil durum planlarını, sigorta politikalarını gözden geçirmeleri; en kötü durum için senaryo geliştirmeleri tavsiye edilmektedir (Childrens Museums Blog, 2020).

AAM'in "Müzelerin Geleceği” başl1klı bloğunda, müdahale yöntemi olarak az, orta ve yüksek düzeyde etkileri olan risk senaryoları geliştirilmiştir. Yüksek düzeyde etki senaryosuna göre, müze ziyarete kapatılmış, dezenfekte edilmiş, evden çalışan müze personeli ise müzenin yönetim kurulundaki iki oyun tasarımcısıyla işbirliği içinde, çevrimiçi bir oyun geliştirerek, oyunla bağlantılı kitlesel bir fon kampanyası başlatmıştır. Böylece hem müzeye gelir sağlanması hem de sosyal izolasyon endişesinin azaltılması öngörülmektedir (AAMa, 2020).

Müzeler, yeni nesil risk olarak kabul edilebilecek salgın hastalıklar ve pandemi sürecine karşı hazırlıklı olmasalar da karantina döneminin başından itibaren hızlı bir şekilde acil durum planları, ilkeler ve standartlar üzerinde çalışarak, mevcut dokümanlarını güncellemişlerdir. WHO, ulusal, bölgesel kurum ve kuruluşların tavsiyeleri doğrultusunda müzelerin koruma ve güvenlik prosedürleri yeniden gözden geçirilmiş; bina, koleksiyon, personel ve ziyaretçi özelinde yeni planlamalar yapılmaya başlanmıştır.

\section{Pandemi Döneminin Müzelere Yönetim ve Finansal Açıdan Etkileri}

ICOM'un "Museums, museum professionals and COVID-19" başlıklı raporunda yer alan araştırmaya katılanların \%94.7'sinin verdiği yanıta göre, müzelerin büyük bir çoğunluğu pandemi nedeni ile Mart ayı ortasından itibaren kapanmıştır. Her ne kadar durum bölgeden bölgeye farklılık gösterse de, her bölgede müzelerin en az \%85.3'ü halen kapalıdır. Müzelerin, Mayıs-Haziran aylarında açılması planlanmaktadır. Araştırmaya katılanların \%12,8'i müzelerinin kalıcı olarak kapanacağını belirtmektedir. ${ }^{8}$ Pandemi döneminde müzelerin \%84'nde kadrolu personelinin çoğunluğu evden çalışmakta; bu süreçte personelin görev ve sorumlukları arasına yeni iş kalemleri de tanımlanmaktadır. Araştırmaya katılanların \%16,1'i işten çıkarıldıklarını, \%22,6's1 ise sözleşmeli personelin sözleşmelerinin yenilenmediğini belirtmektedir (ICOMb, 2020).

NEMO'nun "Survey on the impact of the COVID-19 situation on museums in Europe" başl1klı raporunda yer alan araştırmaya göre ise, Avrupa'daki her 10 müzeden 3'ü serbest çalışanlarla sözleşmeleri askıya alırken, her 5 müzeden 3'ü gönüllü programlarını durdurmuştur. Pandemi sonrası dönemde müzelerin en az $\% 80$ 'nde proje ve program sayısının azalmas1 öngörülmektedir. Avrupa'da her 5 müzeden 3'ü haftada yaklaşık olarak 20.300 Euro'luk kayıp yaşadıklarını; büyük ölçekli ve daha turistik yerlerde bulunan müzelerin ise haftalık kayıpların yüzbinlerce Euro olduğu belirtilmiştir. ${ }^{9}$ Avrupa'daki müzelerin büyük bir çoğunluğu \%70-80 oranında gelir kaybı yaşadıklarını beyan etmiş; 2020 yılı sonuna kadar bilet ücretleri, müze kafeleri ve dükkanlarından elde edilen gelirlerde de büyük oranda azalma beklendiği vurgulanmıştır (NEMO, 2020).

Müzelerin yönetim şekli, organizasyon şeması ve bütçesi bağlı bulunduğu kuruma göre farkl11ık göstermekle birlikte, birçok müze gelirlerini, bilet ücretleri, müze kafesi/restoranı ile müze dükkanındaki satışlar, kiraya verilen mekânlar ya da ücretli etkinliklerden sağlamaktadırlar.

\footnotetext{
${ }^{8}$ UNESCO'nun "Museums around the World in the face of COVID-19" başl1klı raporunda (2020), pandemi döneminde müzelerin \%90'1 ziyarete kapanmış olup, \%10'ndan fazlasının açılamayacağı belirtilmektedir.

${ }^{9}$ Hollanda'daki Rijksmuseum ve Stedelijk Museum, Avusturya'daki Kunsthistorisches Museum gibi büyük müzelerin haftalık gelir kaybı 100.000-600.000 Euro arasindadır (NEMO, 2020).
} 
Yaklaşık olarak 3 ay süre ile ziyarete kapalı kalan ve belki de daha uzun süre kapalı kalacak olan müzelerin ayakta kalabilmeleri için finansal desteğe ihtiyaçları vardır.

ICOM'un 2 Nisan 2020 tarihli açıklamasında, toplum sağlığının ve ekonomik koşulların güvence altına alınmasının öncelikli olduğu; öte yandan insanların, ulusların kimliklerinin önemli bir parçası olan müzelerin ve sahip oldukları koleksiyonların geleceği ile ilgili endişe duyulduğu ifade edilmiştir. Açıklamada, finansal açıdan sınırlı sayıda desteği olan ve bugün geçici olarak kapanan birçok müzenin, gelecekte tamamen kapanma riskiyle karşı karşıya olduğu vurgulanmaktadır. İtalya'da kültür sektörünün 3 milyar Euro, İspanya'da ise sadece Nisan ayında 980 milyon Euro kaybedeceği öngörülmektedir. AAM, A.B.D.'deki müzelerin üçte birinin bir daha açılamayacağını; serbest çalışan ya da sosyal güvencesi olmayan binlerce müze uzmanının kazançlarını kaybetmek üzere olduğu veya kaybettiğini belirtmektedir. Bu çerçevede ICOM, politika belirleyicilere ve karar vericilere müzeler ve çalışanlarına destek vermeleri için çağrıda bulunmaktadir (ICOMd, 2020).

AAM ve Oxford Economics tarafindan hazırlanan verilere göre, A.B.D.'deki müzeler Amerikan ekonomisine yıllık 50 milyar Amerikan doları katkıda bulunmakta ve y1lda 726.000 kişiye istihdam olanağı sağlamaktadırlar. Pandemi döneminde müzelerin günde en az 33 milyon Amerikan doları kaybettiği, müze personelinin görevlerini sürdürebilmesi, kültür mirasının korunması, ulusal ölçekte turizm endüstrisinin yeniden inşa edilmesi için müzelerin Amerikan Kongresi'nin gündemine alınması gerektiği vurgulanmaktadır. Nitekim AAM 19 Mart 2020 tarihinde yayımladığı bildiride, müzelere finansal destek sağlanması konusunda Amerikan Kongresi'ne çağrıda bulunmuş; Amerikan Kongresi'nin yeni koronavirüsün pek çok farklı sektör üzerindeki olası etkileri ile mücadele etmek üzere hızlı bir şekilde hareket ettiğini, ekonomik yardım ve iyileştirme paketleri ile ilgili çalıştığını, bu kapsamda müzelere de destek verilmesinin gündeme alınmasını talep etmiştir (AAMb, 2020).

AAM'in bildirisini takiben Metropolitan Müzesi 24 Mart 2020 tarihinde \#CongressSaveCulture (\#KongreKültürüKurtar) başlıklı bir kampanya başlatmıştır. Müze, kâr amacı gütmeyen sanat kurumları için federal hükümetten en az 4 milyar Amerikan doları mâli destek ve vergi indirimi talep etmektedir (Metropolitan Museum, 2020).

ICOM, AAM, Metropolitan Müzesi gibi NEMO da Avrupa'daki müzelerin finansal kayıplarını azaltmak, personel maaşlarının ödenmesi, ana faaliyetlerin projeler yoluyla sürdürülebilirliğinin sağlanması, müzelerin ek faaliyetleri için yatırımların yapılması yönünde Avrupa menşeli, ulusal, bölgesel ve yerel kuruluşların desteklerini talep etmektedir. Pandemi sonrasında müzelerin tekrar ziyarete tekrar açılabilmeleri için gerekli hijyen ve güvenlik önlemlerini almaları, ihtiyaç duyulan altyapıları oluşturmaları yönünde NEMO da hükümetlere çağrıda bulunmaktadır (NEMO, 2020).

Kültürel belleğin ve toplumsal mirasın koruyucuları olan müzeler ülke ekonomisine katk1 sağlayan kurumlardan biri olmasına karşın, ülkelerin açıklanan ekonomi destek paketlerinde hepsinde yer almamaktadırlar. İstanbul Kültür Sanat Vakfı'nın (IKSSV) Nisan 2020 tarihli "Pandemi Sırasında Kültür-Sanatın Birleştirici Gücü ve Alanın İhtiyaçları" başlıklı raporunda kültür-sanat sektörü ile yaratıcı endüstrilere yönelik destek veren ülkeler sıralanmaktadır. Örneğin; “A.B.D. açıklamış olduğu üçüncü teşvik paketinde kültür-sanat sektörüne 307,5 milyon dolar ayırmış; Almanya hükümeti kültür-sanat, medya ve yaratıcı sektör çalışanları dâhil olmak üzere küçük işletmelere ve serbest çalışanlara destek olmak için 50 milyar Euro ayıracağını duyurmuş; Arjantin Kültür Bakanlığı 30 milyon Arjantin pesosu (450 bin dolar) tutarında acil durum fonu ile kültür kurumlarına destek olmayı hedeflediğini belirtmiştir" (IKSV, 2020).

NEMO'nun "Survey on the impact of the COVID-19 situation on museums in Europe" başlıklı raporunda ise, Avrupa'daki 12 ülkede acil durum kültür fonunun hazır olduğu, 21 ülke ise 
kültür kurumları ile ilgili herhangi bir acil durum fonunun henüz oluşturulmadığı belirtilmektedir (NEMO, 2020).

Müzeleri de içeren kültür-sanat sektörü odaklı destek paketleri ya da acil durum fonları, faizsiz kredi, vergi erteleme ya da muafiyeti müzelerin ayakta kalabilmesine yardımcı olacaktır. Öncelikle küçük ölçekli müzelerin desteklenmesi, devlet ya da özel müzelerin yapacakları proje/fon başvurularının kaynaklarında kesinti yapılmaması da müzelere finansal açıdan destek olacak unsurlardır.

Pandeminin müzelere etkisinin başında finansal sorunlar gelse de, müzeleri kısa ve uzun vadede etkileyecek başka hususlar da mevcuttur. Art Fund'un koronavirüsün müzelere etkisi üzerine yapmış olduğu araştırma ${ }^{10}$ sonucunda elde edilen verilerin derlendiği "COVID-19 Impact: Museum Sector Research Findings" başlıklı özet rapora göre 106 müze müdürünün pandeminin müzelere etkisi ile ilgili görüş ve endişeleri sırasıyla şöyledir (Art Fund, 2020):

- Ziyaretçilerin müzeleri tekrar ziyaret edebilme koşulları (\%85),

- Müze personeli ve ailelerinin sağlık durumları (\%76),

- Müzelerin birlikte çalıştıkları ortaklıkların ertelenmesi veya iptal edilmesi (\%75),

- Müzelerin finansal durumu (\%56),

- Gönüllü desteğinin devam etme şekli (\%48),

- Bina ve koleksiyonların güvenlik koşulları (\%48),

- Personel sayısının azaltılması veya işten çıkarmalar (\%42),

- Müzeye finansal destek sağlayanlar ile iş ilişkilerini sürdürme koşulları (\%34),

- Müzenin kapalı olduğu dönemde koleksiyonların bakımı (\%34),

- Sanatçıların veya serbest çalışanların desteklenememesi (\%32),

- Müzenin kapalı olduğu dönemde güvenlik veya elektrik masrafı (\%31),

- Müzenin hükümet ile ilişkileri (\%30),

- Dış tedarikçiler ile yapılan sözleşmeler (\%28),

- Müzenin işleyişini tekrar gözden geçirmek üzere ihtiyaç duyulan finansal destek (\%17),

- Mütevelli heyeti ile ilişkiler (\%8).

Dünyanın önde gelen ulusal müze birliklerinden biri olan İngiliz Müzeler Birliği'nin (Museums Association-MA) yöneticisi Sharon Heal ile yapılan röportajda, MA'in, üyeleri, hükümet, sponsorlar ve ilgili kuruluşlarla irtibat halinde olduğu; üye müzelerin birçoğunun personeli, gönüllüleri ve ziyaretçileri korumak için önleyici tedbirler aldıkları belirtilmiştir. MA, İngiltere'deki müze uzmanlarından aldığı geri bildirimler doğrultusunda müzecilik alanının hangi açılardan etkileneceğini ve müzelerin nasıl önlemler alabileceklerini şu şekilde sıralamaktadır (Adams, 2020):

- Müze personelinin sağlık sorunu nedeni ile işte olamama durumu, evden çalışan personel sayısının artması, hastalık ödeneği, personele maaş ödenememesi,

\footnotetext{
10 Araştırma, 2020 yılı Nisan ortası-Mayıs başı arasındaki dönemi kapsamakta; "Müze sektörünün bugünkü durumu" ve "Art Fund'un mevcudiyeti” olmak üzere iki bölümden oluşmaktadır. Araştırmada, 106 müze müdürü, 321 müze ve galeri uzmanı ile görüşme gerçekleştirilmiştir (Art Fund, 2020).
} 
- Sağlık önlemleri olarak müzedeki mekânların belirli aralıklarla temizlenmesi, müzede el yıkama ve sosyal mesafe kuralının yaygınlaştırılması,

- Müzenin kapalı olması sebebiyle yaşanacak gelir kaybı,

- İleriye dönük olarak bağış ve fon bulma ihtiyac1,

- Ödünç eserler ve süreli sergilerin durumu,

- Kurumsal itibarın zedelenme olasıllğ

- İlgili koleksiyonlar ve içeriğine nasıl erişim sağlanacağının planlanması.

Bina ve koleksiyonların bakımı ve güvenliği; müzelerin işleyişinin bir parçası olan tam ya da yarı zamanlı personel, gönüllüler ya da ortaklarla süreç yönetimi; ziyaretçi yönetimi; müze mekânlarında ve çevrimiçi olarak etkinlik yönetimi; entelektüel erişimin kapsamının ne şekilde genişleyeceği, müzelerin pandemi sonrası dönemde yeniden planlama yapacağı başlıca konulardır. Müzeler bir yandan ziyarete açılmaya başlarken bir yandan da söz konusu hususlarla ilgili çalışmaya devam etmektedirler.

\section{Pandemi Döneminde İletişim: Dijital Platformlar ve Çevrimiçi Etkinlikler}

UNESCO'nun 2015 tarihli "Müze ve Koleksiyonların Çeşitlilikleri ve Toplumdaki Görevlerinin Korunması ve Geliştirilmesine İlişkin Tavsiye Kararı"nda müzelerin toplumun eğitimi, gelişimi ve refahı yönünde kültür alanındaki rolü ile enformasyon ve iletişim teknolojilerinin önemi vurgulanmaktadır.

$\mathrm{Bu}$ çerçevede, sosyal izolasyon sürecinde birbiri ardına geçici olarak ziyarete kapanan müzeler öncelikli olarak mevcut çevrimiçi deneyim alanlarını ziyaretçilere hatıllatmışlar; ardından geçmiş ya da güncel süreli sergilerin çevrimiçi deneyimlenmesine imkân vermişlerdir. Pandemi döneminde bazı müzeler dijital koleksiyonların, sergi turları ya da yayınların sayısını artırmış, sosyal medya hesaplarını (Facebook, Twitter, Instagram gibi) daha aktif bir şekilde kullanmaya başlamış, bazıları ise çevrimiçi eğitim faaliyetleri, oyunlar ya da yarışmalar tasarlamıştır.

ICOM'un "Museums, museum professionals and COVID-19" başlıklı raporuna göre, pandemi öncesi dönemde müzelerin yarısının sosyal medya hesapları ve çevrimiçi koleksiyonları olsa da, ziyarete kapanan müzelerin çevrimiçi etkinliklerinin \%15 oranında, sosyal medya faaliyetlerinin ise araştırmaya katılan müzelerin yarısından fazlasında arttığı ya da başladığ görülmektedir (ICOMb, 2020).

NEMO'nun "Survey on the impact of the COVID-19 situation on museums in Europe" başlıklı raporuna göre ise, müzelerin ziyarete kapanmasından itibaren çevrimiçi ziyaretlerde $\% 40$ 'dan fazla artış olmuş; araştırmaya katılanların \%70'nden fazlası ise müzelerin sosyal medya hesaplarındaki faaliyetleri arttırdığını belirtmiştir (NEMO, 2020).

ICOM'un konuyla ilgili yayımladığı metinde müzelere dijital platformlar hatırlatılmakta ve entelektüel erişim araçları önerilmektedir. Buna göre (ICOMa, 2020):

- Daha fazla sayıda müze koleksiyonu çevrimiçi erişime açabilir.

- Sanal ortamda müze turları düzenlenebilir.

- Facebook, Instagram, Twitter gibi sosyal medya hesapları aracılığıyla koleksiyonlar ve sergiler ziyaretçilerle paylaşılabilir; Pinterest vasıtasıyla sergiler açılabilir. 
- Müzeler podcast ${ }^{11}$ yöntemini tercih edebilir.

- Hashtag kullanılarak ya da sosyal medya aracılığıyla bilgi yarışmaları düzenlenerek ziyaretçilere erişim sağlanabilir.

UNESCO'nun yeni koronavirüsün müze sektörüne etkisi ile ilgili yürüttüğü araştırma sonucunda hazırlanan rapora göre (UNESCO, 2020); müzeler pandemi öncesi dönemde planladıkları etkinlikleri (süreli sergiler, konserler, konuşmalar vb.) sosyal medya aracıllı̆ıyla canlı yayın olarak ya da kaydederek ziyaretçiler ile paylaşmaya başlanmışlardır. Bu etkinliklerin birçoğu indirilebilir niteliktedir ya da YouTube, SoundCloud gibi dijital platformlardan erişime açılmıştır. Bazı müzeler ise, ziyarete kapalı olan alanlarını (depolar, atölyeler vb.) ya da personelin görev ve sorumluklarını çevrimiçi videolarla paylaşmaya başlamışlardır. Daha katılımcı yöntemler tercih eden müzelerden J. Paul Getty Müzesi ve Rijksmuseum, "Between Art and Quarantine" adlı Instagram hesabı aracılığıyla kullanıcıların müze koleksiyonlarındaki ünlü eserleri yeniden canlandırarak, fotoğraflarını çekip paylaşmalarını teşvik etmektedirler.

Müzelerin sanal ortamdaki faaliyetlerinin öncüsü, 1200 'den fazla sayıda müzenin sanal turuna ya da dijital koleksiyonlarına ev sahipliği yapan "Google Art \& Culture" başlıklı platformdur. Metropolitan Müzesi, Rijksmuseum, Modern Sanatlar Müzesi (Museum of Modern Art-MOMA), Solomon Guggenheim Müzesi, Uffizi Galerisi, Türkiye'den ise Pera Müzesi, Sakıp Sabanc1 Müzesi, İstanbul Modern, Masumiyet Müzesi gibi birçok müze bu platformda yer almaktadır. Müzelerin kurumsal girişimlerine en iyi örnek ise, Hermitage Müzesi'nin 44 sergi salonu ve 588 eser hakkında bilgi veren beş saatlik videosudur (Dawson, 2020).

Çin Halk Cumhuriyeti'nde "Ulusal Kültürel Miras Yönetimi” tarafından düzenlenen acil durum toplantısında, geçici süre ile ziyarete kapanan müzeler ve tarihi alanlar konusu görüşülmüş; hükümet, evlerinde kalan ziyaretçilere dijital araçlar vasıtasıyla müzelerin erişiminin sağlanmasını talep etmiştir. Bu çağrıya 100 kurum yanıt vermiş; merkezi bir portal üzerinden çevrimiçi sergiler paylaşılmaya başlanmıştır. Ayrıca birçok kurum, eğitici oyunlar ve etkileşimli dijital sanat eserlerini sanal ortamda paylaşmaktadır (Whiddington, 2020).

A.B.D.'deki Ulusal Sanat Galerisi, MOMA, Frick Koleksiyonu, J. Paul Getty Müzesi gibi birçok müzenin dâhil olduğu bir diğer girişim ise, \#MuseumFromHome (\#EvdenMüze) sosyal medya hesabıdır. \#MuseumFromHome ile müze koleksiyonları, galeri turları, diğer eğitim ya da eğlence içerikli faaliyetler Twitter ve Instagram hesapları aracılığıyla paylaşılmaktadır (AAMc, 2020). Zürih'teki Dijital Sanatlar Müzesi (MuDA) ise, "Yaratıc1 Korona Sinıfları" (Creative Corona Classes) ${ }^{12}$ başlığı altında sunduğu çevrimiçi etkinlikte, farklı yaş gruplarına göre hazırlanmış farklı türde etkinliklerle (örgü örme, matematik, biyoloji, müzik, film, oyun vb. sinıflar) 5 farklı dilde ziyaretçilere çevrimiçi hizmet sunmaktadır (NEMO, 2020).

NEMO'nun "Survey on the impact of the COVID-19 situation on museums in Europe" başlıklı raporuna göre, eğlenceli, katılımcı, yaratıcı dijital hizmetler müzelerin dijital geleceklerin bir parçası olacaktır. Müzelerin diğer dijital hizmetlerle rekabet edebilmesi için yeterli kaynağa ihtiyaçları olduğu da vurgulanmaktadır (NEMO, 2020).

Öte yandan, Uluslararası Telekomünikasyon Birliği (International Telecommunication Union) verilerine göre, dünya nüfusunun neredeyse yarısının internet erişimi bulunmamaktadır (International Communication Union, 2019). Dolayısıyla dünyada milyonlar insanın dijital

11 Apple, "Bir programın internette bulunabilen bölümleridir. Podcast'ler genellikle orijinal ses veya görüntü kayıtlarından oluşur; ancak bir TV ya da radyo programının, dersin, performansın veya başka bir etkinliğin kaydedilmiş yayınları da olabilir" (https://www.apple.com/tr/itunes/podcasts/fanfaq.html, t.y.).

12 Detaylı bilgi için bkz. https://muda.co/ccc/ (MuDA, 2020). 
platformlar üzerinden çevrimiçi uygulamalara, sanal müzelere ya da müzelerin sosyal medya hesaplarına erişimi mümkün değildir. Bu noktada, her ne kadar çevrimiçi etkinlikler, dijital uygulamalar pandemi döneminde müzelerin ziyaretçi ile iletişiminde tek çözüm yolu olsa da, pandemi sonrası dönemde müzelerin bir yandan hijyen ve sosyal mesafe kurallarını göz önünde bulundurarak mevcut mekânlarında faaliyetlerini sürdürmeleri bir yandan da dijital araçların sunduğu firsatları tekrar gözden geçirerek, ziyaretçilere ne tür çevrimiçi deneyimler hazırlanabileceği yönünde planlamaları olmalıdır.

\section{Sonuc}

20. yüzyılın ortalarından itibaren müzeler toplum odaklı yaklaşımı benimsemişlerdir. Günümüz müzeleri keşfetme ve bilgi edinme mekânları olup, aynı zamanda toplumun buluşma noktası ve nefes alma durağıdır. 21. yüzyılda müzeler bir yandan küresel ekonomik krizden etkilenip, ayakta durmaya ve topluma hizmet vermeye devam ederken, bir yandan da çalışma alanlarını ve faaliyetlerini çeşitlendirme yönünde çaba göstermektedirler.

WHO’nun yeni koronavirüsü pandemi olarak ilân ettiği gün müzecilik alanında da yeni bir dönem başlamıştır. Müzeler her ne kadar diğer insan kaynaklı afetlere hazırlıklı olsalar da salgın hastalıklar ve pandemi konusunda planlamalarının olmadığı ortaya çıkmıştır. Öte yandan müzeler, WHO, ulusal ve bölgesel kuruluşların tavsiyeleri doğrultunda hızlıca hareket etmişler; bir yandan mevcut acil durum planlarını gözden geçirmeye başlamış bir yandan da pandemi dönemi ve sonrasında süreci nasıl yöneteceklerini planlamışlardır. Müzecilik birlikleri ise bu süreçte öncelikle bildiri yayımlayarak müzelerin mevcut durumlarını, pandeminin müzelere kısa ve uzun vadeli etkilerini kamuoyuyla paylaşıp, destek talebinde bulunmuşlar; çevrimiçi anket ve sektör araştırmaları yapıp, raporlar hazırlamışlar; araştırma verilerini ve pandemi ile ilgili pek çok kaynağ 1 dijital olarak yayımlamışlardır.

Toplum nezdinde güvenilir kurumların başında gelen müzelerin pandemi döneminde toplumsal görev ve sorumluluklarını doğru icra edebilmeleri için, toplum sağlığına yönelik tüm bilgi veya mesajların ilgili ulusal ve uluslararası kuruluşlara referans vererek, müzelerin iletişim planı çerçevesinde hazırlanmasına dikkat edilmelidir.

Müze gelirlerinin azalması nedeni ile pandemi sonrasında müzelerin karşı karşıya kalacağı en temel sorun finansal kaynak sıkıntısıdır. Yapılan araştırma sonuçlarına göre bu süreçten en çok küçük ölçekli müzeler ile özel fonlarla yönetilen müzeler etkilenmektedir. $\mathrm{Bu}$ nedenle, ulusal pandemi hazırlık planlarında ve ekonomi paketlerinde kültür sektörüne, özellikle de müzelere destek konusuna yer verilmelidir. Finansal kaynak, koleksiyonların korunması ve güvenliği, personel ihtiyaçları, bina yönetimi için gerekli olmakla birlikte müzelerin sürdürülebilirliği açısından temel ihtiyaçtır.

Son y1llarda müzelerin dijitalleşmesi, dijital platformlar ya da sanal müzelerin daha yaygın bir şekilde tercih edilmesi müzecilik alanında tartış1ırken, pandemi döneminde müzelerin ziyaretçilere tek erişim noktasının çevrimiçi uygulamalar olması kuşkusuz ki mevcut tartışmaları başka bir boyuta getirmektedir. Bu çerçevede, müzeler tüm faaliyet alanlarını tekrar gözden geçirmeli; entelektüel ve olanaklara erişim için neler yapabileceği daha kapsamlı planlanmalı; çevrimiçi etkinliklerle ilgili ziyaretçi araştırmaları yapılmalıdır. Tamamen dijitalleşmek yerine, müzelerin fiziksel mevcudiyetine ek olarak, dijital uygulamaların nasıl etkin bir iletişim aracı olarak kullanılabileceği düşünülmelidir.

Pandemi döneminin müzelere olumsuz yönde etkisi olsa da, bu dönem müzelerin tanımı, işlevleri, faaliyetler alanları, yönetimi ve işleyişi ile ilgili birçok konunun tekrar gözden geçirilmesi için bir firsattır. Müzecilik alanında çalışan kurum ve kuruluşların, müzecilik birlikleri ve üniversitelerin, pandemi özelinde yapmayı planladıkları araştırma projeleri, yürütülen sektör araştırmaları ve analizleri müzecilik alanının gelişmesine katkı sağlayacaktır. 


\section{Kaynakça}

AAMa. (13 Mart 2020). Using Scenarios to Plan Your Museum's COVID-19 (Coronavirus) Response. Centre for the Future of Museums Blog. https://www.aamus.org/2020/03/13/using-scenarios-to-plan-your-museums-covid-19-coronavirus-response/

AAMb. (19 Mart 2020). Urge congress to support museum community economic relief. https://www.aam-us.org/2020/03/19/urge-congress-to-support-museum-communityeconomic-relief/

AAMc. (25 Mart 2020). 4 ways museums can succesfully leverage digital content and channels during coronavirus (COVID-19). https://www.aam-us.org/2020/03/25/4-ways-museumscan-successfully-leverage-digital-content-and-channels-during-coronavirus-covid-19/

AAMd. (2020). American Civil War Museum: COVID-19 Action Plan (Draft). https://www.aamus.org/wp-content/uploads/2020/03/Coronoa-Virus-Strategies_DRAFT-003.pdf

AAMe. (2020). COVID-19 Resources \& Information for the Museum Field. https://www.aamus.org/programs/about-museums/covid-19-resources-information-for-the-museum-field/

Adams, G. K. (12 Mart 2020). Coronavirus: How will it affect museums and what can be done to mitigate the impact? Museums Association News. https://www.museumsassociation.org/news/10032020-coronavirus-impact-museumsgalleries

Art Fund. (28 Mayis 2020). COVID-19 Impact: Museum Sector Research Findings Summary Report. https://www.artfund.org/assets/downloads/art-fund-covid19-research-report.pdf

Apple. (t.y.). Podcast Nedir? https://www.apple.com/tr/itunes/podcasts/fanfaq.html

CCI. (17 Nisan 2020). Caring for Heritage Collections during the COVID-19 Pandemic. https://www.canada.ca/en/conservation-institute/services/conservation-preservationpublications/canadian-conservation-institute-notes/caring-heritage-collectionscovid19.html

Childrens Museums Blog. (28 Şubat 2020). ACM Resources to Help Guide Your Museum's Response to Coronavirus. https://childrensmuseums.blog/2020/02/28/museums-responsecoronavirus/

Dawson, A. (13 Mart 2020). On coronavirus lockdown? The top online museum and art tours to enjoy from home. The Art Newspaper. https://www.theartnewspaper.com/feature/oncoronavirus-lockdown-the-top-online-museum-and-art-tours

Hickley, C. (28 Mayıs 2020). Five European museum directors explain their reopening strategies. The Art Newspaper. https://www.theartnewspaper.com/news/the-long-road-tonormality?fbclid=IwAR1f0TyPb4xyK1TFcesa7MYTKnfZa7bJMoifh_gQ1J84UMBEAMrE-OvRRM

ICOMa. (12 Mart 2020). How to reach -and engage- your public remotely? https://icom.museum/en/news/how-to-reach-and-engage-your-public-remotely/

ICOMb. (26 Mayis 2020). Report: Museums, museum professionals and COVID-19. https://icom.museum/wp-content/uploads/2020/05/Report-Museums-and-COVID-19.pdf

ICOMc. (2020). Conservation of museum collections. https://icom.museum/en/covid19/resources/conservation-of-musem-collections/ 
ICOMd. (2020). Statement on the necessity for relief funds for museums during the COVID-19 crisis. https://icom.museum/en/news/statement-on-the-necessity-for-relief-funds-formuseums-during-the-covid-19-crisis/

ICOMe. (2020). Webinar - Coronavirus (COVID-19) and museums: Impact, innovations and planning for post-crisis. https://icom.museum/en/news/webinar-coronavirus-covid-19-andmuseums-impact-innovations-and-planning-for-post-crisis/

International Communication Union. (2019). Measuring digital development: Facts and figures 2019. ITU Publications. https://www.itu.int/en/ITUD/Statistics/Documents/facts/FactsFigures2019.pdf

İKSV. (Nisan 2020). Pandemi Strasında Kültür-Sanatın Birleştirici Gücü ve Alanın İhtiyaçları. https://www.iksv.org/i/assets//iksv/documents/Pandemi_Sirasinda_Kultur_Sanatin_Birlesti rici_Gucu_ve_Alanin_Ihtiyaclari_Nisan_2020.pdf

Kennedy, R. (04 Haziran 2020). COVID-19 Collections Care Resources. https://www.iccrom.org/sites/default/files/COVID19\%20Collections\%20Care\%20Resources.pdf

Metropolitan Museum. (24 Mart 2020). Metropolitan Museum launches \#CongressSaveCulture campaign to advocate for federal relief funds for non-profit cultural sector. https://www.metmuseum.org/press/news/2020/met-museum-launches-congresssaveculturecampaign

MuDA. (t.y.). Corona Creative Classes. https://muda.co/cce/

Museum of Science. (Mart 2020). Epidemic Disease \& Pandemic Response Policy. https://www.mos.org/sites/develvis.mos.org/files/docs/misc/Museum\%20of\%20Science\%2 0-\%20Pandemic\%20Response\%20Policy.pdf

National Foundation for Infectious Diseases. (22 May1s 2018). \#Outbreak: Epidemics in a Connected World. https://www.nfid.org/2018/05/22/outbreak-epidemics-in-a-connectedworld/

NEMO. (12 May1s 2020). Survey on the impact of the COVID-19 situation on museums in Europe Final Report. https://www.nemo.org/fileadmin/Dateien/public/NEMO_documents/NEMO_COVID19_Report_12.05.20 20.pdf

Sholts, S. (26 Şubat 2020). How museums can help the public make sense of pandemics? Smithsonian Magazine. https://www.smithsonianmag.com/smithsonian-institution/howmuseums-can-help-public-make-sense-pandemics-180974281/

Smithsonian Cultural Rescue Initiative. (2020). COVID-19 Resource Hub. https://culturalrescue.si.edu/hentf/major-disasters/current-disasters/\#top

UNESCO. (May1s 2020). UNESCO Report: Museums around the World in the face of COVID-19. https://unesdoc.unesco.org/ark:/48223/pf0000373530

Whiddington, R. (14 Şubat 2020). Virtual tours and gamification, China's museums pivot content for coronavirus. Jing Travel. https://jingtravel.com/virtual-tours-gamification-onlineexhibitions-chinas-museums-coronavirus/ 